\title{
The orbitozygomatic stich: A technical modification of the lateral supraorbital approach
}

\section{Lazukova, Miroslava}

2016

Lazukova , M , Andrade-Barazarte , H , Makhamov , M , Kivelev , J , Goehre , F , Jahromi , B R , Ibrahim , T F , Araujo , R , Lehto , H \& Hernesniemi , J A 2016 , ' The orbitozygomatic stich: A technical modification of the lateral supraorbital approach ', Surgical Neurology International , vol. 7 , 46 . https://doi.org/10.4103/2152-7806.180770

http://hdl.handle.net/10138/166360

https://doi.org/10.4103/2152-7806.180770

publishedVersion

Downloaded from Helda, University of Helsinki institutional repository.

This is an electronic reprint of the original article.

This reprint may differ from the original in pagination and typographic detail.

Please cite the original version. 


\title{
Technical Note
}

\section{The orbitozygomatic stich: A technical modification of the lateral supraorbital approach}

\author{
Miroslava Lazukova', Hugo Andrade-Barazarte ${ }^{1,2}$, Mahkham Makhamov ${ }^{1}$, Juri Kivelev' \\ Felix Goehre ${ }^{1,3}$, Behnam Rezai Jahromi ${ }^{1}$, Tarik F. Ibrahim ${ }^{1,4}$, Ricardo Araujo ${ }^{1}$, Hanna Lehto ${ }^{1}$, \\ Juha A. Hernesniemi ${ }^{1}$ \\ ${ }^{1}$ Department of Neurosurgery, University of Helsinki and Helsinki University Hospital, Helsinki, Finland, ${ }^{2}$ Department of Neurosurgery, University Central \\ Hospital Antonio Maria Pineda, Barquisimeto, Venezuela, ${ }^{3}$ Department of Neurosurgery, Stroke Center, Bergmannstrost Hospital, Halle, Germany, ${ }^{4}$ Department of \\ Neurosurgery, Loyola University Medical Center, Maywood, IL, USA \\ E-mail: Miroslava Lazukova - lazukovam@yahoo.co.uk;*Hugo Andrade-Barazarte - hugoandrade2@yahoo.es; \\ Mahkham Makhamov - makhkammakhkamov@gmail.com; Juri Kivelev - j.v.kivelev@gmail.com; Felix Goehre - fgoehre@gmail.com; \\ Behnam Rezai Jahromi - behnam.rezai@gmail.com;Tarik F. Ibrahim - tarik.ibrahim@gmail.com; Ricardo Araujo - skullbasefellow@gmail.com; \\ Hanna Lehto - hanna.lehto@hus.fi; Juha A. Hernesniemi - juha.hernesniemi@hus.fi \\ *Corresponding author \\ Received: 28 October $15 \quad$ Accepted: 24 February $16 \quad$ Published: 20 April 16
}

\begin{abstract}
Background: The lateral supraorbital approach (LSO) provides access to a variety of pathologies including anterior and some posterior circulation aneurysms, sellar and suprasellar lesions, and anterior fossa tumors. Technical modifications of LSO improve the surgical exposure of the skull base.

Methods: We retrospectively analyzed 73 consecutive patients treated by the senior author (Juha A. Hernesniemi), at the Department of Neurosurgery, Helsinki University Hospital in Helsinki, Finland from May 2013 to October 2013. This study cohort underwent a modified LSO to access anterior circulation aneurysms, sellar and suprasellar tumors, and anterior fossa tumors. The studied population comprised 30 men and 43 women, with a mean age at treatment of 54 years (9-83 years).

Results: LSO was successfully used to access anterior circulation aneurysms in $59(81 \%)$ patients, $10(14 \%)$ patients with anterior cranial fossa tumors, and $4(5 \%)$ patients with suprasellar tumors. The skull base drilling provided a mean of $6.8 \mathrm{~mm}(1.7-22 \mathrm{~mm})$ in increased exposure.

Conclusion: LSO provides adequate access to vascular and neoplastic lesions of the anterior cranial fossa, by drilling approximately $6.8 \mathrm{~mm}(1.7-22 \mathrm{~mm})$ of the lateral orbital wall and sphenoid wing. This enhances surgical exposure and trajectory. An additional trick while performing an LSO is to place a single or multiple stiches (orbitozygomatic stich) at the base of the dura once opened, eliminating the dead space between the dura and anterior skull base.
\end{abstract}

Key Words: Aneurysm, lateral supraorbital approach, orbitozygomatic stich

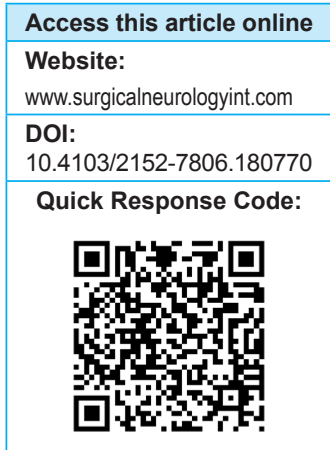

This is an open access article distributed under the terms of the Creative Commons Attribution-NonCommercial-ShareAlike 3.0 License, which allows others to remix, tweak, and build upon the work non-commercially, as long as the author is credited and the new creations are licensed under the identical terms.

For reprints contact: reprints@medknow.com

How to cite this article: Lazukova M,Andrade-Barazarte H, Makhamov M, Kivelev J, Goehre F, Jahromi BR, et al.The orbitozygomatic stich:A technical modification of the lateral supraorbital approach. Surg Neurol Int 2016;7:46.

http://surgicalneurologyint.com/The-orbitozygomatic-stich:-A-technical-modification-of-the-lateral-supraorbital-approach/ 


\section{INTRODUCTION}

The lateral supraorbital approach (LSO) is a simple, more efficient modification of the pterional approach. ${ }^{[15,16]}$ The senior author (Juha A. Hernesniemi) has used LSO in more than 6000 neurovascular and tumor cases over the last 30 years. ${ }^{[6,8-11,13]}$ LSO provide access to a variety of pathologies including most anterior and some posterior circulation aneurysms, sellar and suprasellar lesions, and anterior fossa tumors. ${ }^{[6,8-11,13]}$

The pterional and orbitozygomatic (OZ) approaches require multiple steps making their execution time consuming. ${ }^{[14]}$ One advantage of LSO is avoidance of dissection of multiple layers and extensive skull base drilling. It is more straightforward to perform and requires only approximately $10 \mathrm{~min}$ to complete the bone work. ${ }^{[6]}$

In this report, we analyzed 73 consecutive patients treated through a modified LSO. Our aim is to delineate the technical aspects of the modified LSO including the extent of skull base drilling and maximal dural retraction with an additional OZ stitch as a safe and effective alternative to increase the exposure of the surgical field and trajectory.

\section{METHODS}

\section{Study cohort}

We retrospectively analyzed 73 consecutive patients treated by the senior author (Juha A. Hernesniemi), at the Department of Neurosurgery, Helsinki University Hospital in Helsinki, Finland, from May 2013 to October 2013. This study cohort underwent a modified LSO to access anterior circulation aneurysms, sellar and suprasellar tumors, and anterior fossa tumors. The studied population comprised 30 men and 43 women, with a mean treatment age of 54 years (9-83 years) [Table 1].

\section{Radiological measurements}

For each patient, we analyzed two-dimensional, pre- and post-operative computed tomographic images. The amount of orbital roof and sphenoid ridge bone removed during drilling was assessed by measuring the distance from the orbit's medial wall to the lateral sphenoid wing at the pterion in the coronal images using the "Centricity Radiology RA 600 v 6.1." - standard program (General Electrics Manufacturer) [Figure 1].

\section{Surgical technique}

The basics of LSO have been widely described previously. ${ }^{[6,7]}$ In this report, we focus on the latest adjuncts to the original technique, specifically the additional skull base drilling and dural flap retraction with an extra OZ stitch.

\section{Craniotomy and skull base drilling}

Following a standard $3-4 \mathrm{~cm}$ diameter $\mathrm{LSO}^{[6,7]}$ the lateral part of the anterior cranial fossa (the roof of the orbit)
Table 1: Characteristics of patients treated through a modified lateral supraorbital approach

\begin{tabular}{lc}
\hline & $\boldsymbol{n}(\%)$ \\
\hline Total number of patients & $73(100)$ \\
Women & $30(41)$ \\
Men & $43(59)$ \\
Age at treatment (years) & \\
Mean & 54 \\
Range & $09-84$ \\
Number of patients with intracranial aneurysms & 59 \\
Women & $36(61)$ \\
Men & $23(39)$ \\
Number of patients with anterior cranial fossa tumors & 10 \\
Women & $6(60)$ \\
Men & $4(40)$ \\
Number of patients with suprasellar tumors & $1(25)$ \\
Woman & $3(75)$ \\
Men & \\
Drilling of orbital lateral wall and sphenoid wing (mm) & 6.83 \\
Mean & $1.7-22$ \\
Range & \\
\hline
\end{tabular}

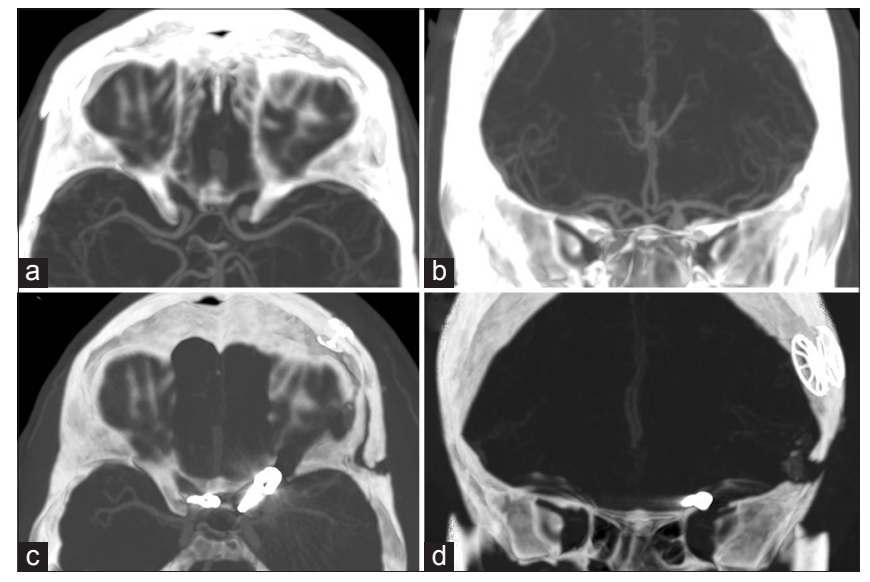

Figure I: Computed tomographic images (a - axial; b - coronal; c - postoperative axial; d - postoperative coronal). Showing a left posterior communicating artery aneurysm and right ophthalmic treated through a left lateral supraorbital approach. Demonstrating the amount of skull base drilling

and the sphenoid ridge are drilled using a $5 \mathrm{~mm}$ ball tip with saline irrigation. We started at the lateral aspect of the orbit before proceeding to the lesser sphenoid wing. Then, a $5 \mathrm{~mm}$ diamond tip without saline irrigation ("hot drilling") is used to stop bone bleeding and smooth the bony surface. The bone should be drilled until the axis of the optical view is in a parallel line with the anterior skull base [Figure 2].

Dural opening and orbitozygomatic stitch technique

The dura is opened in a curvilinear fashion based on the sphenoid bone and retracted anterolaterally. Dural 


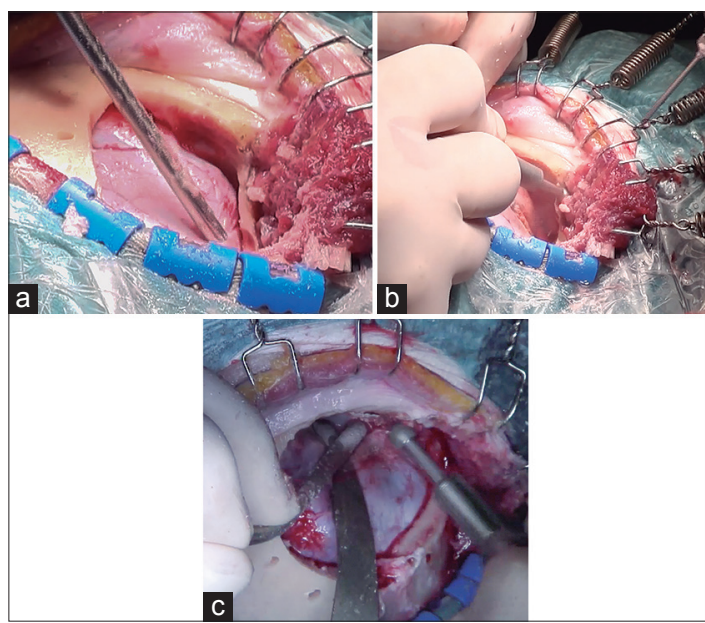

Figure 2: Intraoperative pictures. Performing a right lateral supraorbital approach (a) beginning of the anterior fossa drilling. (b) Drilling of the lateral orbital wall with a diamond tip (lateral view). (c) Drilling of the lateral orbital wall with a diamond tip (superior view)

stitches are applied circumferentially and retracted with artery clips. Then, OZ dural stitch is applied, at the base of the lateral sphenoid bone and dural pedicle base. An interrupted dural stitch is applied in an outward-inward fashion through the whole thickness of the dura at the lower $2 / 3$ of the dural flap and retracted superiorly with artery clips. The width of the base of OZ stitch is up to $10 \mathrm{~mm}$. This allows for further widening of the microsurgical exposure with maximal stretching of the dural flap and obliteration of the dead retro-orbital space resulting from the skull base drilling [Figure 3].

\section{RESULTS}

\section{Pathologies}

LSO was successfully used to access anterior circulation aneurysms in $59(81 \%)$ patients, $10(14 \%)$ patients with anterior cranial fossa tumors, and $4(5 \%)$ patients with suprasellar tumors [Table 1].

\section{Skull base drilling}

The skull base drilling provided a mean of $6.83 \mathrm{~mm}$ $(1.7-22 \mathrm{~mm})$ in increased exposure [Table 1].

\section{DISCUSSION}

The techniques for accessing different pathologies of the anterior cranial fossa have evolved since the first frontotemporal approach described by Dandy in 1918..$^{[1,17]}$ In this report, we present a technical modification of LSO originally described by the senior author (Juha A. Hernesniemi) based on experience of the surgical technique, to provide better access with less skull base drilling compared to the pterional and $\mathrm{OZ}$ approach while providing a wide, safe surgical exposure.

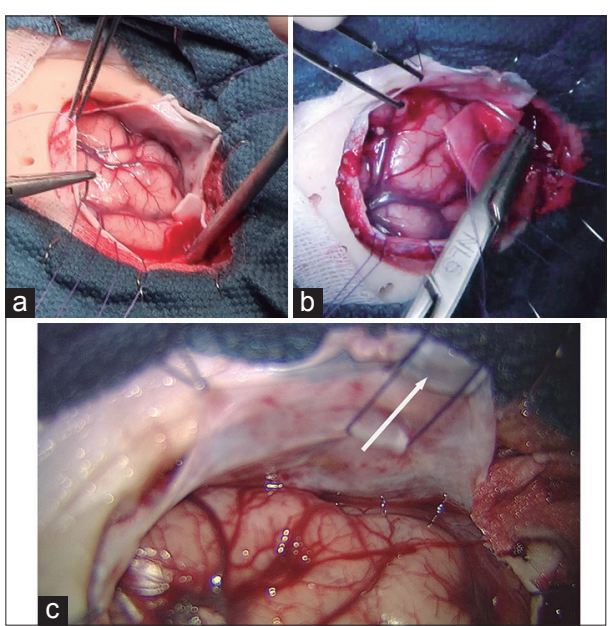

Figure 3: Intraoperative pictures. Dural retraction (a) multiple stitches are used to elevate the dural edges over the craniotomy. (b and c) The orbitozygomatic stitch is placed on the most inferior aspect of the dural pedicle to eliminate the dead space product of the bone drilling or to contain the periorbital fat away the surgical field (white arrow demonstrating retraction direction of the orbitozygomatic stitch)

\section{Surgical cases}

In our series, the modified LSO provided adequate access to pathologies involving the anterior cranial fossa and anterior circulation aneurysms. This is in concordance with previous reports using the same surgical approach and similar approaches. . $^{[3,6,8-13]}$

\section{Skull base drilling}

LSO represents a smaller, tailored craniotomy that can be placed more anteriorly or posteriorly depending on the pathology to be approached. ${ }^{[6,7]}$ The lateral wall of the orbit and lesser sphenoid wing were drilled a mean of $6.83 \mathrm{~mm}$. An advantage of the modified LSO includes sparing additional steps of traditional approaches such as OZ or pterional craniotomies while still offering adequate access to the pathologies previously mentioned. ${ }^{[2,4,5,14]}$

One important consideration during drilling of the orbital roof and wall is the inadvertent opening of the periorbital fascia, causing herniation of the periorbital fat into the surgical corridor. This is addressed with a single stitch placed on the most inferior aspect of the dural pedicle to eliminate the dead space product of the bone drilling or to contain the periorbital fat away the surgical field. The key to the modified LSO is the extra bone removal. This allows for increased access to the skull base. The surgeon's vision and trajectory are maximized, however, with OZ stitch which tacks the dura against the bone and eliminates any dead space. The additional bone removed in the modified LSO is typically not necessary for access to most of pathologies that the standard LSO is used for. When this standard approach is not sufficient, the modified version with the OZ stitch may provide the needed access. 


\section{CONCLUSION}

LSO provides adequate access of vascular and neoplastic lesions of the anterior cranial fossa, by drilling approximately $6,8 \mathrm{~mm}(1.7-22 \mathrm{~mm})$ of the lateral orbital wall and sphenoid wing, the surgical field increased considerably improving the surgical exposure and trajectory. An additional trick while performing an LSO is to place a single or multiple stiches (OZ stich) at the base of the dura once opened, eliminating the dead space between the dura and the anterior skull base.

\section{Financial support and sponsorship}

Nil.

\section{Conflicts of interest}

There are no conflicts of interest.

\section{REFERENCES}

I. Dandy WE. Contributions to brain surgery: A. Removal of certain deep-seated brain tumors B. Intracranial approach with concealed incisions. Ann Surg 1925;82:513-25.

2. Delashaw JB Jr., Tedeschi H, Rhoton AL. Modified supraorbital craniotomy: Technical note. Neurosurgery 1992;30:954-6.

3. Elsharkawy A, Niemelä M, Lehecka M, Lehto H, Jahromi BR, Goehre F, et al. Focused opening of the sylvian fissure for microsurgical management of MCA aneurysms. Acta Neurochir (Wien) 2014;156:17-25.

4. Figueiredo EG, Deshmukh P, Nakaji P, Shu EB, Crawford N, Spetzler RF, et al. An anatomical analysis of the mini-modified orbitozygomatic and supra-orbital approaches. J Clin Neurosci 2012;19:1545-50.

5. Figueiredo EG, Deshmukh P, Zabramski JM, Preul MC, Crawford NR,
Siwanuwatn R, et al. Quantitative anatomic study of three surgical approaches to the anterior communicating artery complex. Neurosurgery 2005;56 2 Suppl: 397-405.

6. Hernesniemi J, Ishii K, Niemelä M, Smrcka M, Kivipelto L, Fujiki M, et al. Lateral supraorbital approach as an alternative to the classical pterional approach. Acta Neurochir Suppl 2005;94:17-21.

7. Lehecka M, Lakso A, Hernesniemi J. Helsinki Microneurosurgey Basics and Tricks. Germany:Aesculap AG; 2011 .

8. Romani R, Elsharkawy A, Laakso A, Kangasniemi M, Hernesniemi J. Complications of anterior clinoidectomy through lateral supraorbital approach. World Neurosurg 2012;77:698-703.

9. Romani R, Elsharkawy A, Laakso A, Kangasniemi M, Hernesniemi J. Tailored anterior clinoidectomy through the lateral supraorbital approach: Experience with 82 consecutive patients. World Neurosurg 2012;77:5I2-7.

10. Romani R, Laakso A, Kangasniemi M, Niemelä M, Hernesniemi J. Lateral supraorbital approach applied to tuberculum sellae meningiomas: Experience with 52 consecutive patients. Neurosurgery 20I2;70:I504-18.

II. Romani R, Lehecka M, Gaal E, Toninelli S, Celik O, Niemelä M, et al. Lateral supraorbital approach applied to olfactory groove meningiomas: Experience with 66 consecutive patients. Neurosurgery 2009;65:39-52.

12. Romani R, Silvasti-Lundell M, Laakso A, Tuominen H, Hernesniemi J, Niemi T. Slack brain in meningioma surgery through lateral supraorbital approach. Surg Neurol Int 201 I;2:167.

13. Salma A, Alkandari A, Sammet S, Ammirati M. Lateral supraorbital approach vs pterional approach: An anatomic qualitative and quantitative evaluation. Neurosurgery 201 I;68:364-72.

14. Sindou MP. Working area and angle of attack in three cranial base approaches: Pterional, orbitozygomatic, and maxillary extension of the orbitozygomatic approach. Neurosurgery 2002;51:1526-7.

15. Yasargil M. Microneurosurgery. Operative Techniques and Pathological Considerations of the Intracranial Aneurysms. Intracranial Arteries. Vol. I. Stuttgart, Germany: Georg Thieme-Verlag; 1984.

16. Yasargil MG, Fox JL. The microsurgical approach to intracranial aneurysms. Surg Neurol 1975;3:7-14.

17. Dandy WE. A new hypophysis operation. Bull Johns Hopkins Hosp 1918;29:154-5. 